\title{
The problem of analysis and evaluation of the programs in a sphere of labor resources territorial mobility
}

\author{
Evgeniia Chagina ${ }^{1, *}$, Kristina Plis $^{1}$, and Ivan Garbuzyuk ${ }^{2}$ \\ ${ }^{1}$ Peter the Great St.Petersburg Polytechnic University, Polytechnicheskaya, 29, St. Petersburg, \\ 195251, Russia \\ ${ }^{2}$ Moscow Polytech University, 107023 B. Semenovskaya Str. 38, Moscow, Russia
}

\begin{abstract}
The article discusses the problem associated with the formation of an approach to the evaluation of the effectiveness of the programs in a sphere of labor resources territorial mobility. On the base of the results of analysis of implementing these programs, the need for using effectiveness as the primary element of the evaluation was proved. It was proposed to use the time and the cost as parameters of evaluation of the effectiveness.
\end{abstract}

\section{Introduction}

Consideration of theoretical and practical aspects of development and management of labor mobility is one of the important aspects of modern science, the social-economic policy of the state and the personnel policy of a single enterprise.

The development of labor mobility systems and programs is an integral part of the labor management system of each individual enterprise. It should be noted that as the size of enterprises increases, the issues and problems of the development of labor mobility more include the territorial aspects of the movement of the labor resources. In most of the cases, this trend is typical for large enterprises, holdings, and companies, subsidiaries of which carry out their economic activities in various territories. In addition, for individual enterprises and for territories in general, at present, one of the main characteristics of the labor market and the source of problems is the personnel shortage. One of the solutions to this problem is the development of programs of territorial labor mobility in the system of the HR of the enterprise, aimed to improve the efficiency of personnel policy and the use of labor resources.

In modern science, there are many theoretical concepts and studies related to the mobility of manpower. In the studies of such scientists as L.S. Blyakhman, A.G. Zdravomyslova, O.I. Shkaratan and other concepts "labor movement" or "personnel movement" reflects the primary form of labor mobility, i.e. movement of labor resources in the enterprise. This approach was developed in the 1920s-1930s. and fairly well investigated [1,2].

Labor mobility in the treatment of it as a movement of labor is seen as migration to other areas (regions) or in a state, as well as between sectors; as a change of place of work, associated with spatial displacement $[3,2]$. An interdisciplinary approach to the interpretation of the concept of "labor mobility" and analysis of processes was used in the works of T.I.

${ }^{*}$ Corresponding author: chagina_j@mail.ru 
Zaslavskaya [2].

Most of the models developed by researchers focus on the relationship between mobility and wages. In the B. Jovanovic's model, mobility is correlated with wages in connection with the relationship between wages and individual characteristics of the employee and the characteristics of the workplace. Within the framework of this model, the author also provides an explanation for the phenomenon of mobility decay with age. [4]

In the study R.H. Topel and M. P. Ward justify the negative impact of starting wages on the likelihood of mobility. Thus, the authors come to the conclusion that the transition to a higher-paying job stabilizes employment. [5] An estimate of the average number of facts of job change and its impact on subsequent earnings is also given in A.Light and K.McGarry work [6].

In modern science, a model of labor mobility based on the concept of human capital, sponsored by R.Ehrenberg and R. Smith, is widely used. Within this model, labor mobility is the voluntary mobility of workers, which is carried out in their own interests in the form of flow, migration, and immigration. Mobility in the labor market is "the process of moving labor to new jobs, which can be accompanied by a change in the type of employment (occupation), territory, employer" [7].

\section{Common approaches and methods for evaluation of the programs in a sphere of labor resources territorial mobility}

In the opinion of the authors, territorial mobility is a set of processes of territorial movement of labor resources, based on voluntary, mutually beneficial principles of labor relations between workers and employers, aimed to eliminate personnel shortage and increase the efficiency of using the labor resources of enterprises.

In modern science, there is no generally accepted approach to determine the effectiveness of activities related to human resources. In particular, this is due to problems with determining the income from such activities. For example, when calculating wages based on the volume of production, sales and, services, it is possible to determine the income from hiring a new employee, which is reflected not only in the scientific but also in the educational literature [8,9]. In this case, the number of goods produced, the sale of goods and the provision of services by a new employee or employees for the relevant period can be considered as income from activities related to the recruitment of a new employee [10]. At the same time, the indicator does not fully reflect the amount of income from activities due to the fact that it does not take into account the importance and role of the labor functions of employees who participated in the implementation of these activities. Determination of the attributable proportion to the total income of a particular event in the personnel or human resource management system requires extensive research. This research should include both elements of analysis and evaluation of the external labor market of the territories, sectoral aspects, reflecting the specificity with respect to labor resources, and comparison with the main aspects of the internal labor market of a particular enterprise. Such a comprehensive study has not been carried out to date.

With regard to programs of territorial mobility of labor resources, the main element of the assessment, in our opinion, is the result. This is due to the fact that quite expensive territorial movement of manpower programs are aimed to address the problems of staff shortages and stabilize the company's human resource capacity.

The staff deficit is a shortage of labor resources in the enterprise [11], i.e. The absence in the enterprise of the required number of employees, characterized by specific, required quality characteristics. Elimination of staff shortages can be viewed as a hiring of the necessary number of employees with the required quality characteristics $[12,13]$. Thus, the basis for elimination of the personnel shortage, and, consequently, the implementation of 
programs of territorial mobility of labor resources is the result. The result, in this case, is not only the recruitment and hiring of the necessary number of employees with the appropriate qualitative characteristics, incl. the level of human capital, but also the compliance with the planned indicators of the results of the implementation of measures for territorial transfers.

Performance is the degree of implementation of the planned activities and achievement of the planned results [9]. With a respect to the specific program of territorial mobility of labor resources, the planned values for each element of the implementation of these programs are determined. This is due to the need for a detailed analysis of the effectiveness of these programs, improving both the systems of territorial movements and the very system of personnel management or human resources of a particular enterprise. Thus, in terms of programs of territorial mobility of labor resources, the main indicator, in our opinion, is the level of effectiveness of activities.

Let's consider the basic directions of realization of programs of territorial mobility of a manpower of the enterprise:

- selection, recruitment of human resources including all the main components of these processes - primary search for candidates, selection, interview, assessment, document flow, etc.;

- implementation of the territorial movement of the candidates, including the relocation of the candidate and his/her family, provision of housing, information support, and (if possible) transport, social infrastructure, etc.;

- adaptation of the new employee, which includes all elements and processes of social and professional adaptation;

- assessment and motivation in the framework of the program of territorial mobility of the labor resources.

\section{The main findings of the evaluation of the effectiveness of measures for the territorial mobility of labor resources}

It seems appropriate to evaluate the impact of measures on the territorial labor mobility based on the following main parameters:

- not constant parameters (costs), i.e. compliance with the planned values by the time of the implementation of activities;

- financial costs - in this case, the implementation of the planned indicators for the costs of implementation of activities and there is the possibility of determining the savings by the program.

An important aspect of the assessment of the effectiveness of territorial mobility programs is also the assessment of changes in the qualitative parameters of the human resources of the enterprise, i.e. conformity of measures to the goals of replenishment, formation, and development of qualitative characteristics of labor resources. In this case, it is possible to consider the above parameters through the essence of the concept of "human capital". At the same time, cost factors are the primary aspects of the analysis and evaluation of the implementation of territorial displacement programs, and aspects related to the change of the qualitative characteristics of personnel, the formation and development of the human capital of an enterprise in the implementation of the programs, require additional research.

\section{A rationale for the application of the proposed parameters for the evaluation of the effectiveness of measures for the territorial mobility of labor resources}


In our opinion, a detailed approach to the analysis and evaluation of the results of the programs of territorial mobility of labor resources is needed, allowing to consider each aspect of the implementation of these programs, to identify problems and prospects for their solution, and to expand the analysis of the human resources management system of the enterprise. Based on this, we propose to evaluate the effectiveness of measures to manage labor mobility for each parameter that characterizes the result of these activities.

It appears that the basis of the analysis of the territorial impact of labor mobility program is the study of the cost structure for these activities. This is typical for the study of both time costs and financial investments. The result of the implementation of the specific activity is the difference between the planned costs of an element of the program for territorial mobility over the period and the actual, current cost value for the same element of the program.

A positive value indicates the saving of time or financial costs on the element of the program of territorial mobility of labor resources, i.e. indicates a positive result for the element. The negative value of the calculated indicators indicates a surplus of funds allocated for the implementation of activities, or a backlog from the schedule of tasks for the elements of the event. In this case, we can talk about the lost profit in terms of financial costs due to the over expenditure of financial resources. With a respect to time costs, a negative result may indicate a loss of time during the implementation of the activity and characterize the decrease in the efficiency of the personnel management department of the enterprise. In case of recruitment of personnel or recruiting agencies at the stages of selection, as well as provision of relaxation services, an increase in time costs may indicate an inefficient choice of the agency. A negative value of the outcome indicators under the mobility program characterizes the savings of both financial and time costs for the element of the event. Equal to zero indicators indicate a clear implementation of the plan for the costs of program activities and to a certain extent indicate the efficiency of the structures that ensure the implementation of programs, in terms of financial costs and time.

A detailed cost analysis of the elements of the implementation of territorial mobility programs will identify savings and over expenditures, optimize future targets for program costs, increase the effectiveness of the analysis of the relationship between costs and qualitative characteristics of the implementation of the programs for territorial mobility of labor. In addition, the analysis of the results in terms of time, in our opinion, is one of the elements of the assessment of the level of efficiency of the personnel management department of the enterprise, which expands the analysis of the effectiveness of this department and the personnel management system of the enterprise.

It seems that the application of this approach will allow a detailed analysis of the costs of measures for the implementation of the programs of territorial mobility of labor resources, identify savings and time costs, their over expenditure, its causes, and expand the analysis and assessment of the efficiency of the personnel management service of the enterprise.

As a result of the analysis of the results of the program of territorial mobility of labor resources, it seems possible and expedient to calculate the effectiveness of programs based on cost factors. Effectiveness is the ratio of actual and planned values for the program. Due to the fact that time can be translated into monetary terms, the ratio of actual and planned costs in this expression can be considered as one of the elements of the effectiveness of the implementation of programs of territorial mobility of labor resources.

Detailed analysis of the efficiency and effectiveness of these programs makes it possible to carry out advanced analysis and assessment of each program element. Consequently, the proposed approach calculates the share of actual costs in the amount of the corresponding planned costs for each element of the program of territorial mobility of labor resources.

The effectiveness of the program of territorial mobility of the company's labor resources, which characterizes a certain level of program effectiveness based on costs, is calculated by the formula: 


$$
E_{p t m}=\sum_{m=1}^{n} \frac{A_{t s 1}}{P_{t s 1}}+\cdots+\frac{A_{t s n}}{P_{t s n}}+\frac{A_{f c 1}}{P_{f s 1}}+\cdots+\frac{A_{f c n}}{P_{f c n}}=\sum \frac{A_{t s}}{P_{t s}}+\sum \frac{A_{f c}}{P_{f c}}=R_{t s p t m}+R_{f c p t m}
$$

where: $A_{t s 1} \ldots A_{t s n}$ - the actual amount of time spent on the element of the implementation of the program of territorial mobility; $A_{\mathrm{fc} 1} \ldots A_{\mathrm{fc}}$ - the actual amount of financial costs for the element of the implementation of the program of territorial mobility; $\mathrm{P}_{\mathrm{ts} 1} \ldots \mathrm{P}_{\mathrm{tsn}}-$ the planned amount of time spent on the element of the implementation of the program of territorial mobility; $\mathrm{P}_{\mathrm{fc} 1} \ldots \mathrm{P}_{\mathrm{fc}}$ - the planned amount of financial costs for the element of the implementation of the program of territorial mobility; $\mathrm{R}_{\mathrm{tsptm}}, \mathrm{R}_{\mathrm{fcptm}}$ - the result of the time and financial costs of the program of territorial mobility, respectively. The calculation of the effectiveness of programs of territorial mobility of labor resources will make it possible to evaluate the implementation of these programs in conjunction with an analysis of the results of the implementation of the program for each specific parameter.

According to the author of the study, it seems possible to calculate the level of effectiveness of programs of territorial mobility of labor resources in terms of cost factors, combining approaches to the evaluation of the results of programs in general and their performance by elements. Under the program performance level $\left(\mathrm{L}_{\mathrm{rptm}}\right)$ we understand the ratio of the totality of results for each element of the program of territorial mobility of labor resources multiplied by the corresponding indicator of the importance of the element in the program, to the results for each element of the program. The calculation is made by the formula:

$$
L_{r p t m}=\sum_{m=1}^{n} \frac{\left(P_{t s 1}-A_{t s 1}\right) * K_{t s 1}}{P_{t s 1}-A_{t s 1}}+\cdots+\frac{\left(P_{t s n}-A_{t s n}\right) * K_{t s n}}{P_{t s n}-A_{t s n}}+\frac{\left(P_{f c 1}-A_{f c 1}\right) * K_{f c 1}}{P_{f c 1}-A_{f c 1}}+\cdots+\frac{\left(P_{f c n}-A_{f c n}\right) * K_{f c n}}{P_{f c n}-A_{f c n}}
$$

At the same time, the indicator of the importance of the element (Kcin) in the program of labor mobility is determined by the share of costs for a specific element of the program in the total expenditure on the program:

$$
K_{c i n}=\frac{q_{c i n}}{Q_{\mathrm{i}}}
$$

qcin - the n-th of costs of the i-th type, attributable to the n-th element of the program;

Qi - total costs of the i-th species under the program of territorial mobility of labor resources.

The type of costs must be considered in the calculation of indicators for time costs separately in monetary and temporal terms. When translating time costs into a monetary expression, a single cost element is considered.

As a result of the assessment and analysis of indicators of the implementation of programs for territorial mobility of the company's labor resources, it is possible to identify the deviation of the current values of the parameters from the program, as well as problems and prospects for the implementation of these programs, which will further enhance their effectiveness. In addition, the application of the approach presented in this study will allow expanding the analysis and assessment of the state and effectiveness of the human resources management system or human resources of the enterprise.

\section{Conclusions}

In conclusion, we note that the territorial mobility is one of the separate types of labor mobility, which reflects a territorial basis, but it has its own specific features. The peculiarities of territorial mobility lie in the fact that its development takes place proceeding from the needs of enterprises in the formation and preservation of human resources, as well as the elimination of the personnel deficit at the expense of territorial movements of labor resources.

The analysis of the effectiveness and efficiency of the programs of territorial mobility of labor resources is based on the analysis of the results based on planned and actual costs for 
each program element. Evaluation of programs of territorial mobility of labor resources should be considered through the indicator of the effectiveness of the implementation of programs for the movement of labor.

It is proposed to evaluate the effectiveness of territorial mobility programs on the basis of two main parameters: time and financial costs, each of which characterizes a particular aspect of the program's effectiveness. In accordance with these parameters, it is proposed to evaluate the level of the program's effectiveness according to the planned and current values of the program implementation.

Analysis of the results of the assessment, the dynamics of changes in indicators will allow evaluating the final results of the implementation of programs, to identify cost savings or overruns, problems, and prospects for the implementation of these programs. In addition, the application of the proposed approach will allow to expand the analysis and evaluation of the effectiveness of the human resources management system of the enterprise and to develop ways to improve its effectiveness.

\section{References}

1. V.F Potudanskaya, T.V. Novikova, V.V. Shalay, Rossiyskoe predprinimatel'stvo 18(240), 35-41 (2012)

2. S.N. Koshkina, Vestnik Omskogo universiteta. Seriya «Ekonomika» 1, 93-98 (2004)

3. A.V. Menzheres, Mobil'nost' rabochey sily $v$ usloviyakh perekhodnogo perioda $k$ innovatsionnoy ekonomike (Kubik, Saratov 2011)

4. B. Jovanovic, Journal of Political Economy 87(5), 972-900 (1979)

5. R.H. Topel, M.P. Ward, The Quarterly Journal of Economics 107(2), 439-479 (1992)

6. A. Light, K. McGarry, Review of Economics and Statistics 80(2), 276-286 (1998)

7. R. Ehrenberg, R. Smith, Modern Labor Economics: Theory and Public Policy. 9th ed. Reading (Addison-Wesley, MA, 2005)

8. B.M. Genkin, Ekonomika i sotsiologiya truda: Uchebnik dlya vuzov, 8-e izd. (Norma Infra-M, Moscow, 2014)

9. Yu. P. Kokin, Ekonomika truda: uchebnik / Yu. P. Kokin, P. E. Shendler (M.: Magistr, 2010)

10. A.R. Bril, O.V. Kalinina, I.V. Ilin, Proc. of the 29th Int. Business Information Management Association Conf. - Sustainable Economic Growth, Education Excellence, and Innovation Management through Vision 2020, 2268-2277 (2017)

11. A.Ya. Kibanov, Ekonomika i sotsiologiya truda: Uchebnik (INFRA-M, Moscow, 2012)

12. R.S. Kaplan, D.P. Norton, Strategy Maps (HBS Press, Boston, 2003)

13. R.S. Kaplan, D.R Norton, Conceptual Foundations of the Balanced Scorecard (HBS Press, Boston, 2010) 